\title{
CONSIDERATIONS ON THE REFORM IN THE POWER SECTOR (AVOIDING CHAOS ON THE PATH TO AN OPTIMAL MARKET STRUCTURE)
}

\author{
lonuț PURICA*
}

\begin{abstract}
The reform of a single player power sector (i.e. a natural monopoly) into a multipleplayers power market brings to the clients not only the benefits of competition but also the costs of complexity. In between the two, an optimal number of players is found, corresponding to the minimum price of power to the clients. Considering time as the third dimension, the optimum curve becomes a potential surface on which the evolution of the market entities is seen as oscillations (mergers and unbundling) along the valley of the minimum price. Every oscillation triggers a price burst, which is detrimental to the clients. To avoid this, the role of the regulator is better defined in the sense of smoothing the transition from monopoly to market. The example of the US and of the EU power sectors evolution is relevant here. In the above approach, long range competition resulting from the future opening of power markets in Europe, or from the penetration, 70 years ago, of the interconnection technology in USA, is compared with the short range (local) competition. Finally, the price limits are determined, which ensure that (i) the new entrants on the market are not eliminated and (ii) the market avoids oscillations (chaotic behavior), which may drastically shock a non-resilient economy. A case study calculation is made for a transition economy (Romania).
\end{abstract}

Key words: unbundling power monopoly, deterministic chaos, power markets, optimization

JEL classification: C5, C62, D4, D5.

\section{Introduction}

A lot is happening these days in the power industries both in Europe (East and West) and in the United States, Australia, etc. The main trend is toward the change of the monopoly dominated national power sectors into power markets. The benefits of the competition implemented through this change are measured by the decrease, in the long run, in the price of energy to the clients. Alas, there is no such thing as a free

*Institute of Economic Forecasting, Bucharest, e-mail: ipurica@pcnet.ro. 
lunch! That is why we try to assess here the price to pay for the benefits of competition that result from the costs of the increased complexity of the market. Can this cost be minimized? Is there an optimal structure of the market which results from the interplay between the benefits of competition and the costs of complexity? Bellow, we are trying to answer these questions, first by defining the behavior of the process and, second, by building conceptual tools that may allow the determination of the best strategies to face the new power market. The role of the regulator is presented in the light of these strategies.

\section{General comments on (market - monopoly - market) cycles}

From the point of view of the information, the cycle of passing from a market economy to a monopoly dominated one (the outmost extreme is a centrally planned one) and back to a market economy shows a hysteresis effect. The passage from market to planned economy is done by nationalization, which triggers a process of information flow from the enterprises level in the market to the centrally-planning entity. In time, no enterprise will know any longer who are the manufacturers of the raw materials and who are the clients for its products, but they will only know that raw materials are taken from a certain store house and that products are to be delivered to another specified store house. It is only the central planner who will have full, real knowledge about the market.

To reverse this process, i.e., to go from planned economy to market, one cannot, simply, reverse the nationalization action into a liberalization one. If the liberalization is done before having re-introduced all the market information back to the level of the enterprises, one will not get a market economy. The only thing obtained is a conglomerate of disconnected enterprises and a number of market information holders, which will use the information to get rich fast. This fast enrichment comes from a high transaction cost resulting precisely from the lack of information. Situations may be encountered where there is almost a monopoly on the transaction costs established by the market information holder.

\section{From power sector to power market}

At present, the power sector in some economies is acting as an "economic sector", where the state is managing through the help of a natural monopoly instrument.

Any natural monopoly in power has developed historically concentrating on the benefits resulted from the economy of scale. This concept has been reflected both on the supply side and on the demand one. On the supply side, the nominal power of power plants has continuously increased, and the fuel, whether imported or bought from the country, was taken in bulk, which allowed negotiation of lower prices. On the demand side, the interconnection technology was extensively used to create the grid for transport and distribution, while more and more customers were connected increasing the scale of the market. Also, regarding the safety of supply, black-outs experienced in operation have triggered measures resulting in a significant improvement of the grid resilience.

Of course, passing to a real market needs competition. Outsiders may come in, both on the supply and on the demand side. This requires a favorable legal environment 


\section{Considerations on the Reform in the Power Sectc}

carefully thought out to lower risk perception. The institutionalization that follows will definitely have to create a regulator for the power market, as well as a system operator to manage the power pool.

\section{The costs of complexity}

An important remark has to be made here: i.e., the fact that in a completely unbounded power generation, part of the benefit of scale, regarding the bulk supply of fuels, is lost. The sum of the costs of numerous smaller quantities of fuel (at higher prices) will result greater at the macro economic level, than the cost of larger quantities bought at smaller prices. Of course, this will happen unless the competition is implemented in the fuel supply too, by, for instance, diversifying the local and the foreign sources of supply. This situation is raising an important comment which has to be made regarding the costs of transaction and the costs of complexity versus the benefits of scale and of competition.

Creating a market for power leads to having a large number of competitors. This is bringing the advantage of competition to the newly defined 'market clients', coming from the former 'sector customers'. At the same time, there is a loss in the benefits of scale, which is felt at the macro economic level (e.g., in the impact of the total cost of fuel on the country's balance of payments). This loss comes from the increased complexity of the market and can, thus, be associated to a measure of the cost of complexity. The cost of complexity may thus be regarded as a marginal transaction cost depending on the increase in the number of power market players. As shown bellow, other mechanisms add up to this cost.

Going to the extremes, one may see that the greater the number of market players, the greater the competition will be, lowering the price to the clients. However, the greater the market complexity, the higher the complexity cost (e.g., by loss of scale benefits, transaction costs and/or other mechanisms), which tends to increase the price to the clients (the increase could be direct or indirect through the macro economic influences).

Since two opposite trends have been identified for the price to the client, we may define an optimum price corresponding to a market complexity where competition benefits are balanced by the cost of complexity.

A qualitative behavior of the process is shown in Figure 1 below.

As more players are penetrating the market the costs of complexity accumulate. The processes that generate the cost of complexity are, in a non-exhaustive list, the following (the estimated figures are given for the cases of various countries, based on the mentioned international sources):

1. The loss of scale benefits for the fuel supply. We think that due to the size of the coal mines, or of the oil tankers, or oil fields, the quantity of fuel delivered is covering the fuel storage capacity of one power plant. Thus, the loss of scale benefits for the fuel supply may not be substantial in the price of fuel if the size of the generating entities is suitably chosen. Diversification of fuel sources may also contribute positively. The estimations made for UK show a loss of benefits as compared to the pro-CEGB situation of USD 2.1 billion for 15 years (19952010) (Newbery and Pollitt, 1997). 


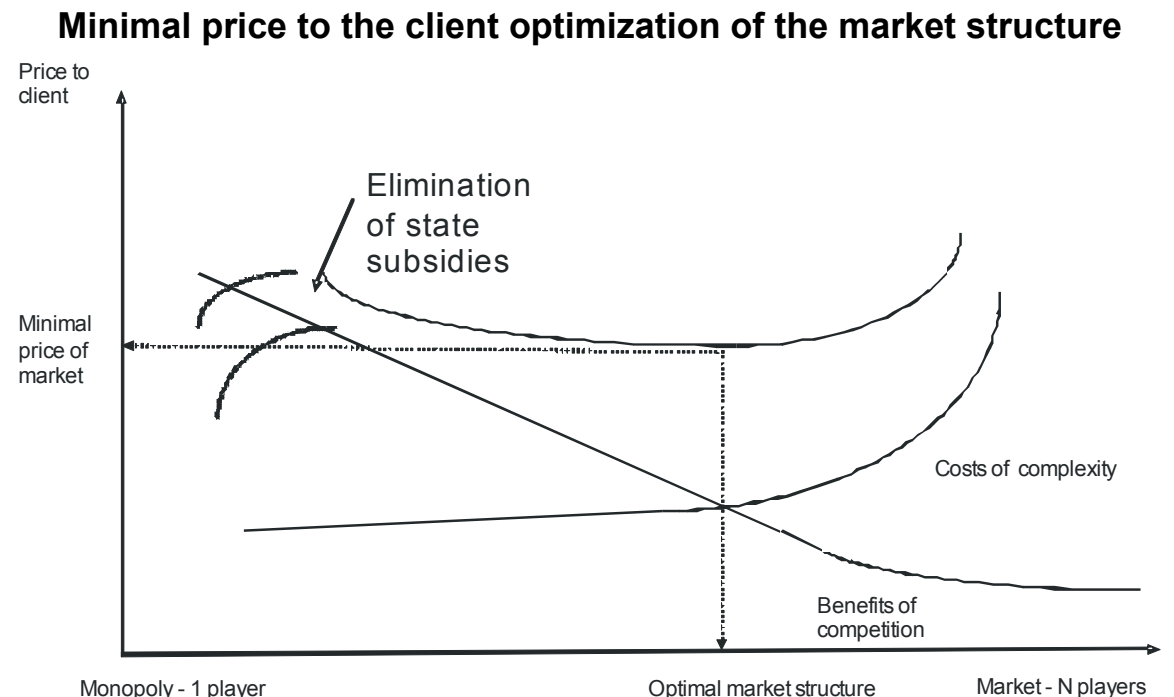

2. The need for an information network which has to be set in place at the level of each player in the market, as well as for the whole market. The costs of this information system are substantial and we may notice that the lack of such a system in the market is liable to produce losses which may add to the cost. Immediately after the unbundling in UK there were significant investments in IT development and implementation (e.g., companies like National Power report figures close to 450 mill. pounds) (source: National Power and UK Electricity Association).

3. Along with the information there is a need for more metering. Setting up manufacturing facilities and installation and maintenance capabilities for that equipment adds other costs. Nevertheless, this situation is creating jobs which may help to absorb the redundant personnel from the power entities, reducing the social conversion costs. Just for information, in Norway the charge for metering is USD 360/year (Livik et al., 1998).

4. Creating and maintaining a market mechanism, e.g., a power pool, as well as a regulatory agency, represents costs which have got to be also sustained. We will discuss later, in more detail, the issue of regulation. To the costs of founding and operating a regulatory agency, there are also some effects on the price of power which are reported (Navarro, 1996) as determining the firms in some EU countries to pay $50 \%$ more for their electricity than do their American counterparts. It is important to note here that passing from a monopoly to a deregulated market cannot be done without a regulatory body, which bears costs and gains stability in the transition. The approach developed here is aiming at reducing these costs by defining in a better context the role of the regulator. 


\section{Considerations on the Reform in the Power Sectc}

5. The professional relocation of the personnel laid off from the previous monopoly, as well as the training of the remaining ones in order to increase their competitiveness is bringing more costs into the picture. The order of magnitude could be roughly 2.8 billion pounds for a 15 years period - as estimated for the UK (Newbery and Pollitt, 1997).

6. Finally, we mention here the transaction cost. It usually results from the increasing number of intermediaries doing the retail wheeling in the market. For example (Conger, 1996), the electric bill of a New Hampshire residential customer includes the following charges:

\begin{tabular}{|l|c|c|c|}
\hline \multicolumn{1}{|c|}{ Description of Charge } & Quantity & Rate & Amount \\
\hline Meter Charge & & 9.16 & 9.16 \\
\hline Transmission Charge & $786 \mathrm{kWh}$ & .00389 & 3.06 \\
\hline Distribution Charge & $786 \mathrm{kWh}$ & .01900 & 14.93 \\
\hline Acquisition Premium & $786 \mathrm{kWh}$ & .02970 & 23.34 \\
\hline Stranded Cost & $250 \mathrm{kWh}$ & .02069 & 5.17 \\
\hline & $536 \mathrm{kWh}$ & .06252 & 33.61 \\
\hline Pilot Participation Credit & $786 \mathrm{kWh}$ & -.01480 & -11.63 \\
\hline PSNH Energy Charge & $786 \mathrm{kWh}$ & .03300 & 25.94 \\
\hline Total Current Charges & & & $\$ 103.58$ \\
\hline
\end{tabular}

Also, transaction costs are brought in by the new power projects; being estimated at $5-10 \%$ of the total project costs (Klein, So and Shin, 1997) - i.e., USD 2 billion to USD3 billion a year assuming that investments worldwide exceed USD 35 billion a year. Most of these costs ultimately will be borne by consumers and taxpayers, although investors may have to swallow the consequences of serious miscalculations.

Where are the benefits which may compensate for these costs, i.e. the benefits of competition? They are coming from the following trends:

1. The increase in efficiency stemming from a better organization and management of the market players; we estimate it to generate a price decrease by around. 10\%, (source: UK Electricity Association- 1994; O. Chisari et al., 1997).

2. The increase in the technological efficiency resulting from the implementation of modem technologies; the assessed value based on the British and Argentinean data is near $30 \%$ decrease in the toe/GWh (see sources at point 1 above).

3. The competitiveness effect of the market on the supply side; it is estimated to reduce prices of electricity by about $10 \%$ (the same sources).

4. The use of the scale benefits by the users which are joining in order to increase the scale of the demand, thus lowering the price, may bring another around $10 \%$ reduction (same sources as above, plus K. Conger - APPA 1996). 
Two other topics should be mentioned here: the security of supply and the need for guarantees by the state, which will foster the inflows of capitals to the power sector.

A good example of the influence that the government's energy investments guarantees policy has on the speed of the reform is the Nuclear Power Plant at Temelin, in the Czech Republic. This case evolved as follows: CEZ - the Power Company of the country - was in a process of spinning off its generation. At the same time, the Czech Government decided to finalize the NPP Temelin project. A foreign company came in with a good offer but which required the state guarantee. The Czech Government did not want to give that guarantee (in order not to increase its already large foreign debt) and asked CEZ to provide it. At this moment, the downsizing of the company stopped, because CEZ had to have enough revenues to be able to cover the required guarantee. Thus, the generation which was taken away amounted to merely $20 \%$ of the total. The process may continue after the Temelin plant will be finished, (source: Pro-Democratia Foundation, 1997).

A conclusion of the story above is that the creation of a market of power, with several smaller players, is only possible if the government or any designated entity assumes the costs of guarantees for investments in power projects. If this is not happening, then, either the size of the power companies must be large enough to sustain guarantees, or the size of the new power projects (e.g. power plants) built into that economy will be downsized. Guarantees represent an increased cost to the government, but they buy out the future existence of the power system's operational capability.

The other important topic we wanted to mention was the safety of supply. From fuel abundance on the market, coming from diversified sources, to the availability of power at any time, to the existence of a continuous distribution service and appropriate maintenance, this involves various economic layers working in inter-correlation.

We may identify the:

1. Physical layer of the technologies used to convert energy;

2. Information layer of the data related to the system operation, finance, etc.;

3. Commercial layer of the actions ensuring the inter-relations among the parties involved (generators, operators, clients, etc.);

4. Financial layer of the flows of money serving, among other, to maintain the working capability of the physical layer, etc.

It is important to notice here the fact that the nominal operation of the power system is influenced by the processes within each layer, while the safety of supply depends strongly on the inter-correlation among the layers.

Considering the four layers one may define the safety of supply in relation to each of them. Thus:

- at the physical layer, the main parameter to consider is the reliability of the technologies used - it is the only remedy against low frequency high consequence events like a total black-out;

- at the information layer, it is the timeliness of the data allowing fast quality decisions. The interplay of information with technology may better help to avoid the low frequency high consequence events.

56 Romanian Journal of Economic Forecasting - 3/2006 - 


\section{Considerations on the Reform in the Power Sectc}

Moving toward the commercial and the financial layers we enter the field of high frequency low consequence events. The protection against these can be achieved through:

- contract design to minimize risk (this also depends on the market structure) at the commercial level and;

- the set up of a sound insurance policy for covering and distributing risk. A captive insurance company may generate some more financial resources which could be used for direct investments or/and guarantees.

\section{Determining the optimal structure of the market}

We will consider now the optimum resulting from the two opposite trends described above. Let us take the case of the EU directive. The discussion following is only a very rough attempt to put some figures in the qualitative trends explained above.

In the graph bellow, it was assumed that the power sector will be segregated as various entities including generation, transport, and distribution. We did not consider the ownership of these entities but, they may include, e.g., a state owned nuclear power generator, independent power producers, public utilities, etc., the same variation being possible on the distribution side, including the brokers. The number of these entities depends on the number of clients, which is measured by the percentage of the market which is opened to competition.

The important assumptions, related to the costs of complexity, are summarized bellow:

1. the transaction cost increases with the number of entities in the market;

2. the metering costs are also sensitive to the number of clients in the open market;

3. other costs vary slightly with the number of players and may be considered as initial costs required by the setting up of the market;

4. the dependence of the variable costs of complexity on the number of entities is assumed to be linear, i.e., $2 \%$ of power price increase for every new entity coming to the market. This is a very rough approximation and in Appendix $1 \mathrm{a}$ more detailed discussion is made on this topic. Also, we assume that the number of companies acting into the power market is proportional with the percentage of market opened to competition.

In these conditions, if we consider the timing of the EU directive, in terms of market opening, and the expected decrease in power prices (Chevalier, 1998), we get the graph presented in Figure 2.

One may see that with the very rough assumptions made above the resulting demo optimal percentage of market opening is $33 \%$. Of course, this figure should be taken only for demonstration purposes. A lot of analysis is required in order to determine a real optimal value and to see how this optimum varies with the different components of the costs and of the benefits and how the costs of complexity could be lowered in order to take advantage of the competition benefits. However, since this is outside our scope we will, instead, make some considerations on the time evolution of the market, concentrating on the aspect of regulation. 


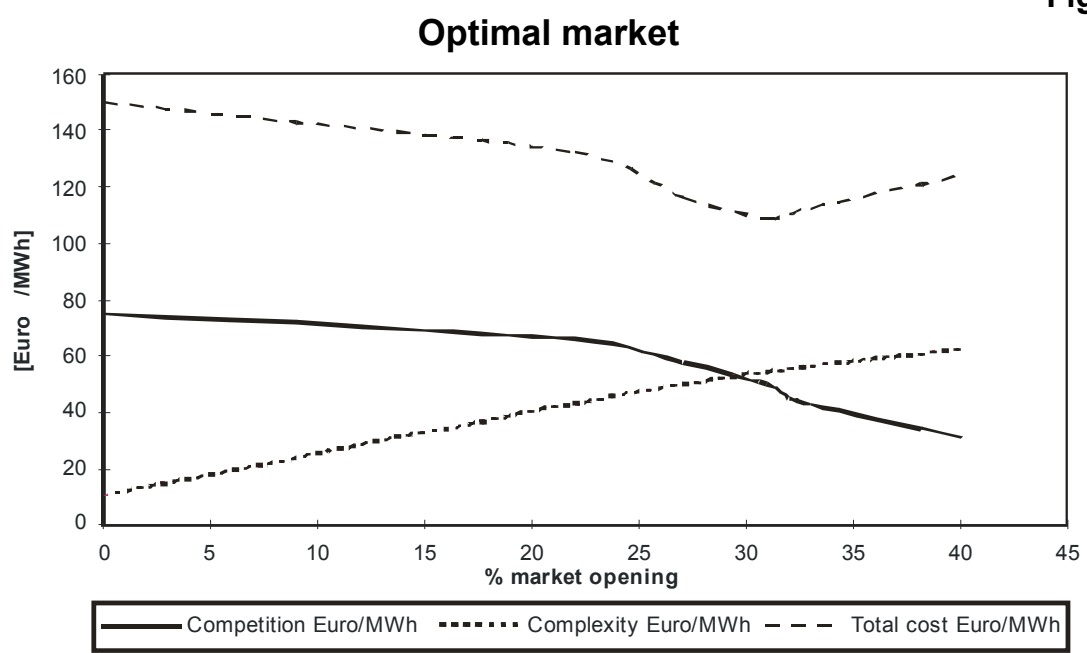

Figure 2

\section{Time evolution of the market entities}

Let us look at Figure 1, to which we add a third dimension, i.e., the time. The optimum curve becomes a surface having a valley of optimum. In this representation, the time evolution of the number of the entities in the market, which could increase by new entrants or decrease (e.g., by merging, buy-out, etc.), is seen as a curve oscillating on the two sides of the optimum valley, eventually converging to it. If we project this curve on the two planes, namely that describing the time evolution of the number of enterprises and the one of the price, we see that each change in the number of entities is leading only to the increase in the price over the optimal value. These price shocks can only be detrimental to the clients. To mitigate them, a new special entity is needed in the market, i.e., the regulator. Considering this approach, the role of the regulator becomes better defined in relation to the market evolution. The regulator must speed up the convergence time to the market optimum by diminishing the number of oscillations of the market entities' number. It should also ensure a smoother penetration of the newcomers. By doing this, the number of price shocks to the market is diminished, with a beneficial effect to the economy as a whole.

Another behavior that is resulting from the interpretation above is concerning the case of the border elimination in the European Union. This is creating more competition, which leads to reducing the local markets power costs to the clients, without actually increasing too much the cost of local complexity. This leads to a displacement of the minimum in the price-entities surface toward the left, i.e., toward fewer entities in the market. This shows that the expected effect of the overall European grid opening will be a merging of power entities in the local markets. The same effect in the USA is given by the interconnection technology penetration, which led the private power entities to merge, being exposed to more fierce, long range competition, while the local entities did not merged to the same level, being confined to service mainly their local areas, without being interested in long range competition. 
Figure 3

\section{Time evolution of the market}

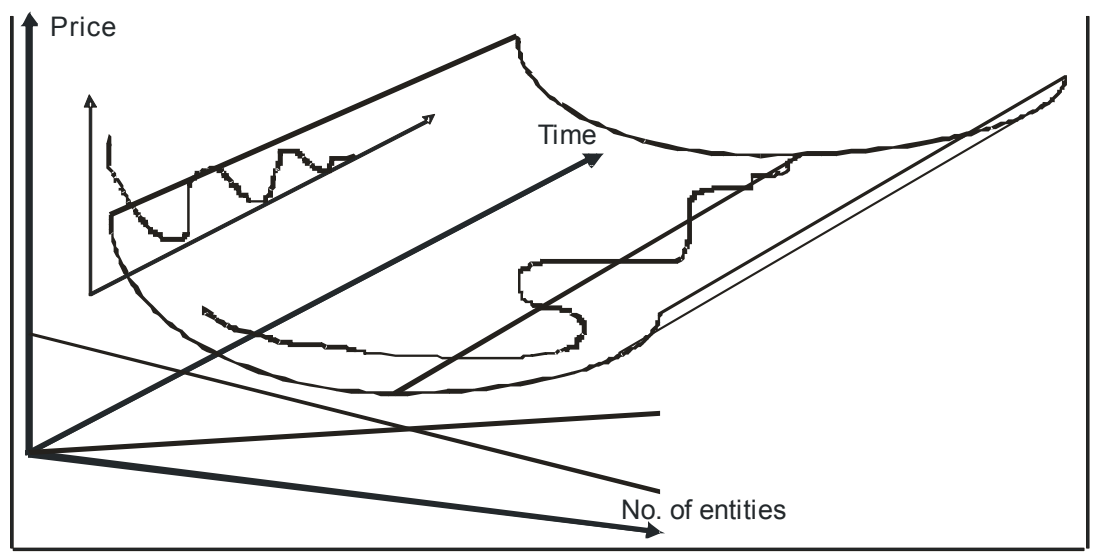

To substantiate the above statement, we give bellow the evolution of the number of entities, in the United States power sector, along the years. The occurrence of regulation (FERC) and of the interconnection technology, have had a strong damping effect on the public utilities oscillation and led to the smooth penetration of the latecomers rural power cooperatives.

Figure 4

Evolution of the power market in the USA (Source APPA-1996)

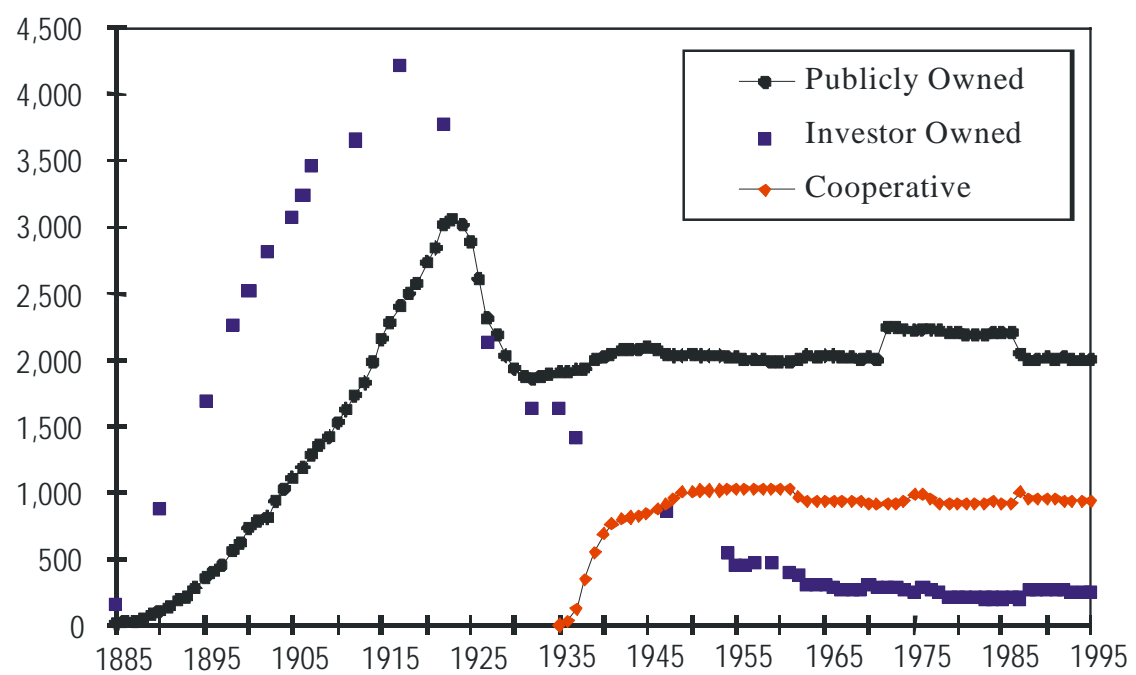


One comment to make here relates to the fact that, by contrast to the USA at the end of the $19^{\text {th }}$ century, the power sectors of today's Europe are not starting from nothing. The companies are not forming themselves as the new technology penetrates but, the existing natural monopolies in power are segregating and the whole market is restructuring.

To illustrate this trend, let us present here the evolution of the number of companies in Hungary, Poland and Romania during the period of power monopolies unbundling in those economies.

Figure 5

\section{Unbundling the power monopoly}

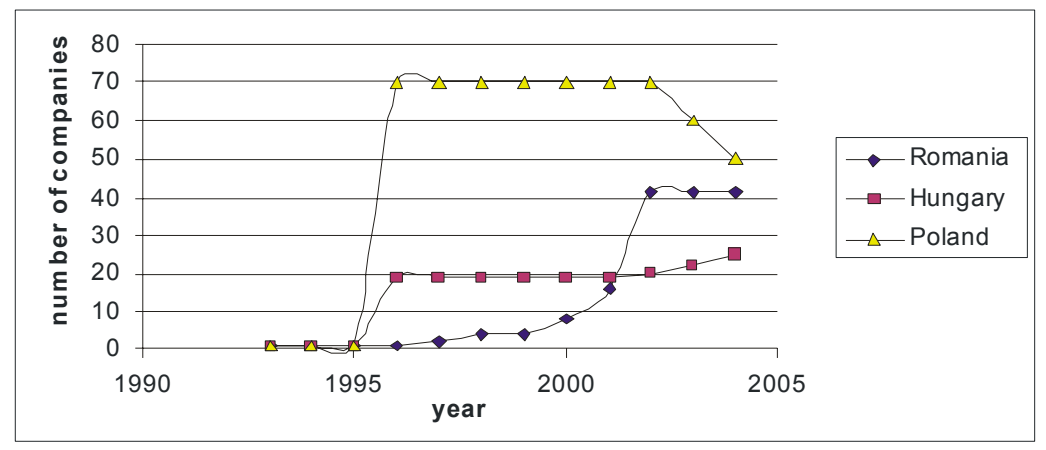

One may notice the fact that Poland unbundled from the beginning into many companies inducing large complexity costs that drive merging, while Romania went smoothly avoiding shocks. Hungary is a special case where the initial market structure was a single buyer (government owned) that was changing latter on to market with the associated economic shocks.

What are the limits of the speed of penetration of the private power companies on a monopoly dominated market? Based on the argument of the economic resilience (capability of an economy to absorb shocks and still operate) there are, presently, two approaches:

- The small steps approach, which tries to minimize the shock by distributing it in time. The possible criticism of this approach is that by taking small steps one may never reach the new better structure in a finite amount of time. The risk of the privates' extinction is very high in this case.

- The sudden change approach, which tries to minimize the shock by reducing it to only one - even if relatively large - instead of having to suffer several smaller, successive ones. The critics here are related to the capability of a weak economy to resist this first shock without being severely damaged. One shock could be beneficial, if it would take the market directly to the optimal structure. If this is not the case, the market will tend to its optimal structure inducing, thus, subsequent shocks which add up to the first. 


\section{Considerations on the Reform in the Power Secto}

The following is an attempt to identify a third way out, where the penetration may be smooth enough, through the limited involvement of a regulator. This may be done through the identification, and use, of the non-linearity in the market behavior.

\section{Non-linear effects in market penetration}

Recent years have revealed the possibility to apply a number of newly found mathematical objects, like 'deterministic chaos', 'catastrophe theory', 'bifurcation theory', etc., to the description of economic systems' behavior.

These instruments have been proved to be more accurate descriptors of several types of non-linear dynamic systems, arriving, thus, at the identification of certain specific mechanisms by which the outcome of complex, 'chaotic', behavior may be predicted.

One such mechanism is shown to occur in the process of privatization of monopolies or, equivalently, it may be applied in the transition of the centrally-planned economies to market ones.

Some comments on the rate of privatization and its role in producing chaotic evolution are concluding the paper.

Appendix 2 is giving some comments about the earlier dynamic models in economics and about the essentials of 'deterministic chaos' behavior generated by quadratic phase diagrams. This behavior occurs also in various economic situations.

\section{Quadratic phase diagrams in economics}

Let us analyze the way the "hill-shaped" dynamic relationships can arise in economics starting with a simple example showing this pattern:

Consider the relationship between a firm's profits and its advertising budget decision. Suppose that without any expenditure on advertising the firm cannot sell anything. As advertising outlay rises, total net profit first increases, then gradually levels off and finally begins to decline, yielding the traditional hill-shaped profit curve. If $P_{t}$ represents total profit in period $t$ and $y_{t}$ is total advertising outlay, $P_{t}$ can, for illustration, be expressed as $P_{t}=a_{t}\left(1-y_{t}\right)$. If the firm devotes a fixed proportion, $b$, of its current profit to advertising outlays in the following period so that $\mathrm{y}_{\mathrm{t}+1}=\mathrm{bP}_{\mathrm{t}}$, the first equation is transformed into our basic chaos one with $w=a . b$.

The reason the slope of the phase graph turns from positive to negative in this case is clear and widely recognized. Even if an increase in advertising outlay always raises the total revenue, after a point its marginal net profit yield becomes negative and, hence, the phase diagram exhibits a hill shaped curve.

Giving it some thought, one may see why the time path of $y_{t}$ can be expected to be oscillatory. Suppose the initial level of advertising, $y_{0}$, is an intermediate one that yields a high profit figure $P_{o}$. That will lead to a large (excessive) advertising outlay y1 in the next period, thereby bringing down the value of profit figure $\mathrm{P} 1$, and, in turn, it will reduce advertising again and raise profit and so on ad infinitum.

The thing to be noticed about this process is that it gives good reason to expect the time paths of profit and advertising expenditures to be oscillatory. However, it does not give us any reason to expect that these time paths need either be convergent or perfectly replicatory. This is an example of how chaotic behavior patterns can arise. 
Another example has been provided in the theory of productivity growth (Baumol and Wolff, 1983). It involves the relationship between the rate of productivity growth $\left(P_{t}\right)$ and the level of R\&D expenditures by private industry (r). Obviously a rise in $r$ can be expected to increase $\mathrm{P}_{\mathrm{t}}$. However, since research can be interpreted as a service activity with a more or less fixed labor component, its costs will be raised by productivity growth in the reminder of the economy and the resulting stimulus to real wages. This, in turn, will cut back the quantity of R\&D demanded. The result, as a formal model easily confirms, will be a cycle with high productivity rates leading to high R\&D prices, which restrict the next period's productivity growth, and so reduce R\&D prices, and so on. If R\&D costs ultimately increase disproportionately with increases in productivity growth it is clear that the relation $P_{t+1}=f\left(P_{t}\right)$ can generate the sort of hill-shaped phase graph that is consistent with a chaotic regime.

Another model that can generate cyclical or chaotic dynamics is a standard growth model of Solow type in which the propensity to save out of wages is lower than that for profits. Suppose that at low levels of capital stock K one obtains increasing marginal returns to increased capital and the elasticity of substitution of labor for capital is initially low; but diminishing returns eventually set in and the elasticity of substitution moves the other way. Then, total profits can rise, first, relative to total wages, but later profits may fall both relative to wages and even absolutely. This can generate a hillshaped relationship between $K_{t+1}$ and $K_{t}$ as rising $K_{t}$ at first elicits rising savings and then, eventually, depresses them as profits fall.

Other similar models may be constructed exhibiting chaotic behavior. The one following relates to the privatization of a monopoly (Purica, 1994).

\section{Privatization of a monopoly}

The characteristic total revenue $\left(R_{m}\right)$ of a monopolist is another typical case of a hillshaped process: at zero quantity demanded $(Q)$ total revenue is zero, while at a price of zero, $R_{m}$ is zero although the quantity demanded is positive. The slope of any line from the origin to the $R_{m}(Q)$ curve is the marginal price of the item at the corresponding output level.

If we consider now the perfect competition market, it is obvious that the total revenue $R_{c}$ will have a linear dependence on the quantity demanded.

The process of passing from the monopolistic market to the perfect competition one is characterized by the shift of the total quantity demanded from the monopolistic production to the private one.

Thus, in the year $y_{t}$ the monopolistic production dominates the market providing all the quantity demanded and obtaining a total revenue given by the parabolic equation

$$
R_{m}(Q)=m \cdot Q(I-Q)
$$

where $Q$ is the ratio between the actual demand and the total potential demand of the economy.

Let us suppose that in the next year, $y_{t+1}$, part of the demand $Q(i . e . r Q)$ is provided from private sources, which gives a total perfect competition revenue $R_{c}=p .(r . Q)$, with $\mathrm{p}$ being the price of the private production. 


\section{Considerations on the Reform in the Power Sectc}

Further on, we may consider that the perfect competition revenue $R_{c}(t+l)$ is proportional to the pervious year's monopolistic revenue: $q \cdot R_{m}(t)$; where $q$ is an indication of the rate of privatization.

Resuming the suppositions above one obtains:

From the equations (1) and (2) we have

$$
\begin{gathered}
R_{m}(t)=m \cdot Q(I-Q) \\
R_{c}(t)=p \cdot(r . Q) \\
R_{c}(t+l)=q \cdot R_{m}(t)
\end{gathered}
$$

which, together with (3) gives :

$$
R_{m}(t)=m /(p . r) . R_{c}(t)\left(1-R_{c}(t) /(p . r)\right)
$$

$$
R_{c}(t+l)=q \cdot m /(p \cdot r) \cdot R_{c}(t)\left(1-R_{c}(t) /(p \cdot r)\right)
$$

Relation (5) represents a typical process where 'chaotic' behavior may occur. In order to bring it to the canonical form we have, as a first alternative, to make the assumption that p.r=I. This is actually saying that the share of the demand $r$ that the private competitors may hope to cover is inversely proportional to the price $p$ which they use on the market, which represents a sensible conclusion.

We have that q. $m=w$ is the parameter we have discussed above regarding the outcome of chaos. Considering the limits emerging in the dynamics and focusing on the relation between the monopolistic parameter $\mathrm{m}$ and the privatization parameter $\mathrm{q}$, we have:

q. $m<1$, the phase curve will lay bellow the 450 line in the first quadrant; and the process will show a tendency of private revenue extinction.

$1<\mathrm{q} . \mathrm{m}<3$, there will be a positive value equilibrium point at the intersection of the 450 line and the parabolic curve; the private revenue converging to it, as a stable state.

We may notice that:

$1<q . m<2$, the phase curve slope at the intersection point will be positive;

$2<\mathrm{q} . \mathrm{m}<3$, the slope will be negative but less than unit in absolute value;

q. $m>3$, the slope will be less than -1 ; the private revenue will start oscillating, experiencing first various doublings of the period, then passing to a chaotic regime.

Analyzing how this translates into considerations on the privatization rate $q$ it results easily from the inequalities above that:

$\mathrm{q}<(\mathrm{I} / \mathrm{m})$ gives an extinction of the privatization process; this representing a lower limit to the privatization bellow which it is inefficient to pursue it.

$(1 / m)<q<(3 / m)$ gives an interval where the private revenue will converge to a stable value. Since this value will increase with the privatization parameter value going up, there is a strong tendency toward a fast privatization.

$(3 / \mathrm{m})<\mathrm{q}$; beyond this limit the private revenue starts oscillating tending to a very complex ('chaotic') behavior, thus, seemingly unpredictable.

Figure 6 is synthesizing an image of the behavior described. 
Privates penetrating the monopoly dominated market

Figure 6

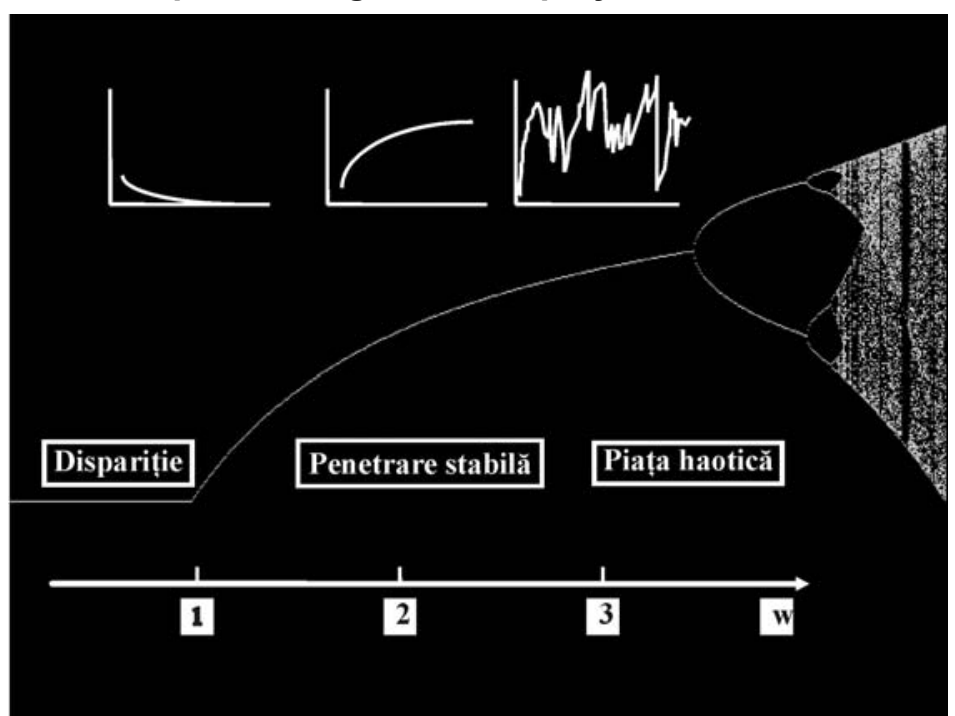

- If now we consider equation (5) and, instead of putting the condition p.r=I, we re-scale $R_{c}$ as $R=R_{c} /(p r)$ we obtain:

(6)

$$
R=(q \cdot m /(p, r)) \cdot R(l-R)
$$

Next, we will present the numerical data resulted from analyzing the historical data in the power sector of Romania, where RENEL, the local monopoly, was corporatized (into CONEL) and is now on the way to being unbundled and privatized.

\section{Numerical data - The Romanian case}

In Romania, the Electrical Energy Authority (RENEL) was generating around 96\% of the electricity and $40 \%$ of the heat required by the economy.

Considering the 1989-1996 data on the sales of electrical energy for low, medium, and high voltage and the total revenue of the public utility presented in the Appendix 1, we may determine the value of $m$ and the one of $w=(q . m / p . r)$.

These values result from a parabolic regression of the data $R[M \$]=R(Q[M W h])$ and $R(t+l)=f(R(t))$.

The resulting values are: $\mathrm{m}=0.047[\$ / \mathrm{kWh}]$ and $\mathrm{w}=1.61$.

The conclusions drawn are the following:

1. Since $w=1.61>1$, we have the confirmation that it was a good time, in 1998 , to have private entities penetrate the power generation.

2. Considering that the fraction of the private supply of electrical energy $(r)$, is the same with the fraction of private income $(q)$, hence that $(q / r)=1$, we have the following limits for the price $p$ of the private suppliers of electricity in a hypothetical privatization of the energy domain. 


\section{Considerations on the Reform in the Power Sectc}

2.1. $\mathrm{q} / \mathrm{r}{ }^{*} \mathrm{~m} / \mathrm{p}<1 \Rightarrow \mathrm{p}>\mathrm{m} ; \mathrm{p}>0.047[\$ / \mathrm{kWh}]$ extinction of privates; from a technological prospective the prices of energy from combined cycle plants were significantly lower.

2.2. $1<\left(q / r^{*} \mathrm{~m} / \mathrm{p}\right)<3=0.016<\mathrm{p}<0.0468[\$ / \mathrm{kWh}]$ penetration by the private suppliers of the energy market;

2.3. $\mathrm{q} / \mathrm{r}^{*} \mathrm{~m} / \mathrm{p}>3=>\mathrm{p}<0.016[\$ / \mathrm{kWh}]$ the penetration of the private suppliers may oscillate in a chaotic manner hardly controllable by the energy policy makers (and by the regulator). This price limit is given by the nearly $25 \%$ of hydrogeneration existing in Romania. (e.g., in Brazil the average power prices went to even lower values from 1992 to 1998).

\section{Conclusions}

The important conclusions resulted from the approach developed above are underlining:

a) The fact that the benefits of competition are balanced by the costs of the increased complexity of the market. There exist an optimal number of players in the market giving a minimum price to the clients. In various markets where, for example, there is too much unbundling, the trend of the market would be toward merging to reach the optimal structure. (Poland may be an example of this sort these days).

b) The process of privatizing monopolies, especially in the economies whose structures are rapidly changing, may lead to complex dynamic regimes ("chaotic"), uncontrollable by the policy makers.

c) The privatization rate is bounded both bellow and above: too slow leads to extinction of the privates, while too fast leads to chaotic regimes liable to produce shocks on a low resilience economy. The penetration of too many privates may reach a point when the shock would not be sustainable any more and 'chaotic' regimes may show up mainly at the commercial and financial levels. (The situation of the IPPs in Pakistan, in 1998, may be a relevant example).

d) The safe price range for the consistent penetration of the privatization is determined for the case of the electricity production in Romania. By keeping the power prices within these limits the regulator may achieve the smooth change in the power sector which avoids the unbearable shocks to the economy. As the market evolves these limits may change.

e) The existence of an optimal market structure (number of entities for a minimum price to the clients) and of an optimal time path (giving a minimum shock to the economy) may create a basis for the design of a power market and of its regulatory framework before a natural monopoly is broken. This possibility shows that one-large-step approach is the best provided: (i) the path trajectory from monopoly to market, and (ii) the target structure of the market are the optimal ones. Thus subsequent shocks are eliminated and the path is smooth. 
Institute of Economic Forecasting

\section{Appendix 1}

\section{Comments on regulation}

The regulatory aspect is very important to the market. Regulation, as our paper shows, has to enhance the competition balancing between the short range and the long range players in the market. From the point of view of the market player's action range, regulation is usually associated with the short range action, while deregulation is associated with letting longer range players compete in the local markets.

There are significant opportunities for gains in deregulating power markets. Table 1 below shows (J.L.Guasch and R.W.Hahn, 1997) the electricity prices in Europe and the United States. To the extent these prices reflect incremental costs, there are likely to be significant gains from reducing entry barriers into different markets. For example, strict regulations in Germany require domestic companies to purchase electricity from regional producers, even though lower cost power is often available nearby. The extent of the potential gains for consumers is difficult to estimate, but in the United Kingdom, energy deregulation resulted in a $70 \%$ increase in productivity and an $18 \%$ $21 \%$ reduction in franchise contract prices (Organization for Economic Cooperation and Development, 1996). The absence of similar deregulation in other European Union countries has led to firms paying over $50 \%$ more for their power than do their American counterparts. Moreover, the impact of higher energy prices on the overall economy can be quite significant. For example, (Navarro, 1996) a $30 \%$ increase in electricity prices tends to raise the price of goods such as paper and pulp, metals, chemicals and glass by roughly $2.5 \%$.

Table 1

\section{Effects of too much (protective) energy regulation in the European Community (cost rounded to the nearest cent per kWh) - source Electricity Association Services Ltd., 1996}

\begin{tabular}{|l|c|c|c|}
\hline Country & Cost & Country & Cost \\
\hline Germany & 12 & France & 7 \\
\hline Italy & 10 & Netherlands & 7 \\
\hline Portugal & 10 & United States & 7 \\
\hline Belgium & 9 & Greece & 7 \\
\hline Spain & 9 & Denmark & 6 \\
\hline Britain & 8 & Finland & 6 \\
\hline Luxembourg & 8 & Norway & 5 \\
\hline Ireland & 7 & Sweden & 4 \\
\hline
\end{tabular}

\section{Appendix 2}

\section{Earlier dynamic models}

The roots of the economists' interest in complex dynamics are to be found in the nonmathematical literature on business cycles, with its large number of models, 


\section{Considerations on the Reform in the Power Sectc}

undertaking to provide a set of conditions sufficient to generate oscillatory behavior in economy.

In the 1930's, the work of Frisch (1933), Lundberg (1937) and Samuelson (1939) started using difference and differential equations in models that generated deterministic time paths.

A non-trivial example is Samuelson's multiplier accelerator model (1939), which is made up of the three standard relationships:

$$
\mathrm{Y}_{\mathrm{t}}=\mathrm{C}_{\mathrm{t}}+\mathrm{I}_{\mathrm{t}} \quad \mathrm{C}_{\mathrm{t}}=\mathrm{cY}_{\mathrm{t}}+\mathrm{k} \quad \mathrm{I}_{\mathrm{t}}=\mathrm{b}\left(\mathrm{Y}_{\mathrm{t}-1}-\mathrm{Y}_{\mathrm{t}-2}\right)
$$

where $Y$ is national income (output), $C$ is consumption, $c$ is the marginal propensity, and $\mathrm{I}$ is investment. The $\mathrm{C}$ equation is a linear consumption production with a oneperiod lag. The investment function is a linear lagged accelerator with investment assumed proportionate to the preceding period's rate of growth of the output. Substitution of the latter two equations into the last one yields

$$
\mathrm{Y}_{\mathrm{t}}=(\mathrm{C}+\mathrm{b}) \mathrm{Y}_{\mathrm{t}-1}-\mathrm{b} \mathrm{Y}_{\mathrm{t}-2}+\mathrm{k}
$$

which is Samuelson's second order linear difference equation.

Out of these types of model four qualitative behaviors were generated:

1. oscillatory and stable (i.e., converging with oscillations of decreasing amplitude toward some fixed equilibrium value);

2. oscillatory and explosive (cycles with divergent amplitude);

3. non-oscillatory and stable;

4. non-oscillatory and explosive.

It was soon recognized that linear equations of an even higher order than Samuelson's would not generate time paths any different from the ones above. This range of possible time paths configurations simply was not sufficiently rich for the economists' purposes, since in reality time paths are often more complex and many oscillations do not seem to explode or dampen toward disappearance.

A solution, brought to attention by Hicks and Goodwin, was the nonlinear modeling, considered of a general form:

$$
y_{t}=f\left(y_{t-1}, \ldots, Y_{t-h}\right)
$$

Responding to real economic issues these authors, for example, showed that such a non-linear model can yield a stable limit cycle toward which all possible time paths of the variable $Y_{t}$ converge. This is where matters were left, the work stopping short of introducing a degree of non-linearity sufficiently great to generate chaotic behavior.

\section{Essentials of chaotic behavior}

In essence, the chaos theory shows that a simple relationship that is deterministic but non-linear, such as a first order nonlinear difference equation, can yield an extremely complex time path.

Inter-temporal behavior can acquire an appearance of disturbance by random shocks and can undergo violent, abrupt qualitative changes, either with the passage of time or with small changes in the values of the parameters. Chaotic time paths can have the following attributes, among others: 
Institute of Economic Forecasting

a) a trajectory (time path) can sometimes display sharp qualitative changes in behavior, like those we associate with large random disturbances (e.g., very sudden changes from small amplitude to large amplitude cycles and vice versa), so at least some tests of randomness cannot distinguish such chaotic patterns of change from "truly random" behavior;

b) a time path is sometimes extremely sensitive to microscopic changes in the values of the parameters which can completely transform the qualitative character of the path;

c) they may display in a bounded region an oscillatory pattern which is very "disorderly".

Chaos theory provides, both for the economic analyst and for the policy designer, warnings that apparently random behavior may not be random at all, demonstrating the dangers of extrapolation and showing the difficulties that can beset economic forecasting generally.

\section{Complex cyclical patterns}

The simplest and most common chaos model involves a nonlinear one-variable difference equation of first order, that is, one of the form:

$$
\mathrm{y}_{\mathrm{t}+1}=\mathrm{f}\left(\mathrm{y}_{\mathrm{t}}\right)
$$

whose graph (the phase diagram) showing $f\left(y_{t}\right)$ as a function of $y_{t}$ is hill shaped and tunable; in other words, the height, steepness, and location of the hill can be adjusted as desired by a suitable modification in the values of the parameters of $f\left(y_{t}\right)$, This phase diagram is the geometric instrument used to analyze the chaotic behavior time path generated by a difference equation model.

The function most commonly used to illustrate the chaos phenomenon is the quadratic equation with a single parameter, $\mathrm{w}$

$$
y_{t+1}=f\left(y_{t}\right)=w y_{t}\left(1-y_{t}\right) ; \text { where } d y_{t+1} / d y_{t}=w\left(1-2 y_{t}\right)
$$

There are different behaviors of the path in the phase-space for the same starting point $y_{\circ}$ and for various values of $w$.

As may be seen from the equation if

$\mathrm{w}<1$ the phase curve will lay bellow the $45^{\circ}$ line in the first quadrant;

$w>1$ there will be a positive value equilibrium point at the intersection of the $45^{\circ}$ line and the parabolic curve;

$1<w<2$ the phase curve slope at the intersection point will be positive;

$2<w<3$ the slope will be negative but less than unity in absolute value;

$w>3$ the slope will be less than -1 .

The last case is the one when the chaotic behavior may set in after a number of frequency bifurcation of the emerging limit cycles (from 2 frequencies to 4 frequencies, etc.). Since, for example, Grandmond and Malgrange (1986) and Baumol and Benhabib (1989) are giving extensive descriptions of the phase space of this equation for the economic dynamic case. 


\section{Considerations on the Reform in the Power Secto}

\section{References}

Baumol, W.J., "Unpredictability, Pseudorandomness and Military Civilian Budget Interactions", Revista Internationale di Science Economiche et Commerciali, April 1986, XXXIII:4, 297 -318.

Baumol, W. J. Benhabib, " Chaos: Significance, Mechanism, and Economic Applications", Economic Prospectives - A Journal of the American Economic Association, Vol. 3, No. I, Winter 1989.

Baumol, W. J. Wolff, E. N. "Feedback from Productivity Growth to R\&D", Scandinavian Journal of Economics, 1983, 85:2, 147-57.

Chevalier Jean-Marie, Electricity Privatization in Europe: Decreasing Prices, Increased Complexity, Cambridge Energy Research Associates, 1998

Chisari Omar, Estache Antonio, Romero Carlos, "Winners and Losers from Utility Privatization in Argentina", Policy Research Working Paper No.1824, The World Bank, September, 1997.

Conger J. Kurt, (APPA), "Competitive Benefits of Coexisting Private and Publicly Owned Electric Utilities", Romania National Energy Conference, September, 1996.

Electricity Association, U.K. Electricity ‘94, London, 1995.

Electricity Association Services Ltd., International Electricity Prices, Issue 23, London, 1996.

Frisch Ragnar "Propagation Problems and Impulse Problems in Dynamic Economics"; Economic Essays in Honor of Gustav Cassel, London 1933.

Grandmond Jean Michel, "Periodic and Aperiodic Behaviour in Discrete Onedimensional Dynamical Systems", in Hildenbrand, W and A Mass Coliel, eds., Contributions to Mathematical Economics, New York North Holland, 1986.

Guash J.Luis, Hahn W. Robert, "The Costs and Benefits of Regulation", Policy Research Working Paper No.1773, The World Bank, June, 1997.

Klein Michael, So Joe, Shin Ben, "The Cost of Privatization Transactions-Are They Worth It ?", The Private Sector in Infrastructure Strategy Regulation and Risk, The World Bank Group, 1997.

Livik Klaus, et al., "Consequences for tariffs and end-use after deregulation Experience from the Norvegian utility industry", Deregulation of the Nordic power market, Implementation and experience 1991-1997, World Bank Seminar, 1998.

Lundberg Erik, Studies in the Theory of Economic Expansion, London, PS King 7 Sou Ltd., 1937.

Navarro Peter, "Electric Utilities: The Argument for Radical Deregulation, Harvard Business Review, 74(1), 112-125 January-February, 1996.

Newberry David M., Pollitt Michael G., "The Restructuring and Privatization of the U.K. Electricity Supply-Was It Worth It?", The Private Sector in 
Institute of Economic Forecasting

Infrastructure Strategy Regulation and Risk, The World Bank Group, 1997.

Pro-Democratia Foundation, Electric Industries Development in Eastern Europe, Seminar, Bucharest, 1997.

Purica Ionuț, "Chaotic Behavior in Privatizing Monopolies", World Energy Council Seminar, Neptun, Romania, 1994.

Samuelson P.A., "Interaction Between the Multiplier Analysis and the Principle of Acceleration", Review of Economics and Statistics, May 1939, 21, 75-78. 